\title{
Culture and Knowledge Transfe: Theoretical Considerations
}

\section{Jing Liu}

School of Economics and Management, Northwest University of Politics and Law, Xi'an, China.

Email: ljta.0417@yahoo.com.cn

Received October $30^{\text {st }}$, 2009; revised December $19^{\text {th }}$, 2009; accepted January $27^{\text {th }}, 2010$.

\begin{abstract}
Knowledge and culture are indissolubly linked together in organizations. Considerable evidence supports the importance of culture in the success or failure of knowledge management. Then, the effectiveness of knowledge transfer needs both cultural understanding and new considerations in the knowledge transfer of intercultural organizations. This paper identifies the influence of different dimensions of culture on knowledge transfer in different types of knowledge. Based on a topology that classified national culture into four dimensions provided by [12,13], power distance and individualism/collectivism are chosen as the representatives of national culture in this work and discuss the effect of national culture on knowledge transfer. The aim of this paper is to propose a theoretical framework for knowledge transfer processes based on differences in national culture for future research.
\end{abstract}

Keywords: Knowledge, Knowledge Types, Knowledge Transfer, Culture, Cultural Dimensions

\section{Introduction}

There are diverging opinions the question of whether culture might influence knowledge management. Reference [1] believes that there is a convergence of approaches with regards to knowledge management and that effective knowledge management may evolve to become a universal concept. Several researchers have found no evidence that differences in national culture have an affect on knowledge management practices [2-4]. But there are considerable evidence supports the importance of culture in the success or failure of knowledge management within organizations. Reference [5] is very critical of the viewpoints ignoring culture influence on knowledge management. He point out that these viewpoints gives the impression that knowledge management operates in a kind of unitary vacuum in which diversity in terms of language, cultural and ethnic background are compressed into one giant independent variable which is in any case pushed to the side. Reference [6] agree and state that knowledge management models that exclude the influence of national and regional culture seriously undercut their potential effectiveness particularly in global applications. They suggest that "cultural bias exists in data bases and in all business and innovation" and that "western analytical assumptions about knowledge and information management, dominates both informa- tion and knowledge management research and development”. Recently, a few researchers have found empirical evidence that differences in national culture do affect knowledge sharing $[7,8]$.

Knowledge and culture are indissolubly linked together in organizations. Recent technological revolution, accompanied by rapid globalization [9], has led to increased cultural heterogeneity within organizations. As the world becomes more and more globalized, western organizations now have access to a pool of job candidates from increasingly diverse cultural backgrounds [10]. National borders no longer preclude individuals of different cultures from working in international organizations. Consequently, organizations today exhibit more cultural diversity among their employees. Simultaneously, advancing globalization is forcing organizations to engage in alliances and networks with partners with widely diverse national or ethnic cultural backgrounds. The differences in the cultural orientation of the collaborating organizations increase the risk of misunderstandings and conflicts, and often lead to failure, but if managed in a balanced manner may also improve performance [11]. To overcome these barriers to success, we need both cultural understanding and new considerations in the knowledge transfer of intercultural organizations.

The effectiveness of knowledge transfer is directly related to the type of knowledge involved in the transfer 
process. In addition, the transfer of knowledge is moderated by 1) the nature of transacting cultural patterns and 2) the cognitive styles of the individuals.

The paper comprises five sections. In the next section, the author will introduce a conceptual framework for different types of knowledge and discuss the effect they impose for knowledge transfer. The third section first discusses the characteristics of culture and then proposes a classification scheme based on a topology that classified national culture into four dimensions provided by $[12,13]$. In the fourth section, power distance and individualism/collectivism are chosen as the representatives of national culture in this work and discuss the effect of national culture on knowledge transfer. A discussion on the theoretical and managerial implications concludes the study.

\section{Theoretical Considerations: Knowledge and Knowledge Types}

In order to articulate knowledge transfer we need a basic conceptualization of the concept of knowledge. The academic question of how knowledge should best be defined is a subject of a lively epistemological debate. The complex nature of knowledge has been discussed extensively in information technology (IT), strategic management, organizational theory and knowledge management literature. Reviewing crucial literature, principally there are two approaches to defining knowledge. One uses the concept of a value chain or hierarchical structure among data, information, and knowledge. The other focuses on the analysis of the process of knowing.

The most common way to describe knowledge is to distinguish it from data and information [14,15]. Reference [16] suggests that knowledge is authenticated information and information is interpreted data. Reference [17] regards data as carrier of information and knowledge, information as relating to descriptive and historical fact, and knowledge as new or modified insight or predictive understanding. Reference [18] defines data as observation or facts, with information as data in a meaningful context and knowledge as meaningfully organized accumulation of information. Reference [19] regards knowledge as a production that is made from raw material - information. Reference [20] argues that data can be classified as raw numbers, images, words, and sounds derived from observation or measurement. Information represents data arranged in a meaningful pattern. Unlike information, knowledge is about beliefs, commitment, perspectives, intention and action. The common factor of those definitions is that knowledge is located at the top of a hierarchical structure.

Another thought defines knowledge as a process related to application [18-22]. Reference [23] identifies both justified belief and commitment anchored to the overall epistemological structure of the holder as key ingredients of knowledge. Reference [15] further adds to this definition of Nonaka and Takeuchi that to know is to be able to take part in the process that makes the knowledge meaningful. Reference [24] concludes that knowledge is a high-value form of information that is ready to be applied to decisions and actions.

One impact of these definitional differences occurs when discussing knowledge transfer. The differences in viewpoints on knowledge suggest different implications for knowledge transfer. It is common to consider knowledge as arranged in a knowledge hierarchy, where data is transformed into information, and information is transposed into knowledge.

A further key question of knowledge transfer research concerns the relationship and interaction among different types of knowledge. Reference [25] note that there are at least three distinct types of knowledge: human knowledge, social knowledge, and structured knowledge. Human knowledge constitutes what individuals know or know how to do, is manifested in important skills, and usually comprises both explicit and tacit knowledge. It could be conceptual or abstract in orientation. Social knowledge exists in relationships among individuals or within groups. Social or collective knowledge is largely tacit, composed of cultural norms that exist as a result of working together, and its salience is reflected in our ability to collaborate and develop transactional relationships. Structured knowledge is embedded in organizational systems, processes, rules, and routines. This kind of knowledge is explicit and rule based and can exist independently of the knowers [26].

These three types of knowledge work in concert with terms of the three dimensions of knowledge, proposed by [27]: simple versus complex, explicit versus tacit, and independent versus systemic. The first dimension- simplicity versus complexity-is relevant in cross-border knowledge transactions. Complex knowledge evokes more causal uncertainties and conveys such types of knowledge required amount of factual information. Simple knowledge can be captured with little information and is, therefore, relatively easy to transfer. The explicit versus tacit dimension concerns how well articulated or implicit the knowledge is. The transfer of tacit knowledge requires richer context and richer media, because tacit knowledge requires more than just codification. Explicit knowledge, however, can be codified and is transferred with relative ease. The third dimension of knowledge deals with the independent versus systemic character of knowledge-that is, the extent to which the knowledge is embedded in the organizational context. Knowledge that is independent can be described by itself, whereas knowledge that is systemic must be described in relation to a body of knowledge existing in the transferring organization. 
Using these dimensions, human knowledge can be conceptualized as either simple or complex, as tacit or explicit (or both), and, generally, as more independent or systemic. Social knowledge can be either simple or complex and is largely tacit and systemic in character. Structured knowledge is either simple or complex, is usually more explicit than tacit, and is largely systemic in character. "Sticky" knowledge [28], which is more complex, tacit, and systemic, is more difficult to transfer, regardless of cultural differences. Some combinations of human, social, and structured knowledge can take on the character of sticky knowledge and become even more difficult to transfer, regardless of the cultural differences involved between the transacting organizations.

Reference [27] argue that the position of knowledge along each of the three dimensions affects the amount of information required to describe it and the amount of effort needed to transfer it. Therefore, it is more difficult to transfer and to absorb if the type of knowledge (human, social, or structured) being transferred is tacit, complex, and systemic.

All of these criteria of effective knowledge transfer are affected when knowledge transfers involve transacting organizations that are located in dissimilar cultural contexts. Cross-border transfer of organizational knowledge is most effective when the type of knowledge (i.e., human, social, or structured) being transferred is simple, explicit, and independent and when such transfers involve similar cultural contexts. In contrast, transfer is least effective when the type of knowledge being transferred is complex, tacit, and systemic and involves dissimilar cultural contexts.

\section{Culture and Cultural Dimensions}

The type of knowledge being transferred is the most important antecedent of effectiveness. However, it should be noted that there are strong interactions between cultural patterns and cognitive styles. In addition, some cultural contexts might foster some cognitive styles that are uniquely responsible for the evolution and practice of certain types of organizational knowledge, compared to other cultural contexts, which might emphasize different styles.

Culture is "a pattern of basic assumptions -- invented, discovered, or developed by a given group as it learns to cope with its problems of external adaptation and internal integration - that has worked well enough to be considered valid and, therefore, to be taught to new members as the correct way to perceive, think and feel in relation to those problems" [29]. Researchers suggest different manifestation of culture. Reference [25] notes that values, norms, and practices are reflections of culture, while [30] categorizes culture into values and practices subsuming symbols, heroes, and rituals. No matter how researchers define culture, however, there is a common view that culture has at least two layers: the inner layer and the core. The core of culture is value, which is described as a fairly stable emotional tendency to respond consistently to some specific object, situation, person or category of people [31]. It's an invisible, unconscious, and embedded basic feeling that is manifested in the outer visible layer of culture, such as attitudes and practices, and in alternatives of behaviors [25-32]. The key role of culture in organizations is creating a consensually validated system of beliefs and values which influences organizational behavior [33].

Culture can be applied to different dimensions, such as nations, organizations, religious groups, and so on. National culture (external culture) and organizational culture (internal culture) are widely accepted as important cultural dimensions for organizations. National (external) culture is national, regional, composed of values, common perceptions, similar views of reality, while organizational (internal) culture is emerging from group mechanics, relevant in understanding the sub-populations who make up the firm [33]. These two dimensions have been regard as a dominant influence on organizational behaviors. National culture is believed to play significant roles in determining the efficacy of knowledge transfer within the same organization that cross different national borders and cultures [34]. Reference [12,13] provided a topology that classified national culture into four dimensions: Power Distance, Individualism/Collectivism, Uncertainty Avoidance, and Masculinity/Femininity. This topology is being adopted for the current study because it provides the most rich and well articulated conceptualization of culture available.

Power distance Power distance can be conceptualized as the degree of separation between individuals at adjacent levels of rank. Individuals who score highly on power distance place a high value on societal hierarchy, while individuals who score low value societal hierarchy less [13-35]. Norms and customs in high power distance cultures include centralized decision making at the top, showing a great deal of respect for individuals with higher rank [36], and a tendency to form bureaucratic organizations [13].

Individualism/Collectivism Several scholars such as [37] regard the individualism-collectivism dimension of cultural variation as the major distinguishing characteristic in the way that different societies analyze social behavior and process information. Reference [38,39] has defined individualism as a cultural pattern consisting of loosely linked individuals who view themselves as independent with their own preferences, needs, rights, and contracts, whereas collectivism refers to a cultural pattern that consists of closely linked individuals who see themselves as belonging to one or more collectives (e.g., family, organizations) and who are motivated by the norms, duties, and obligations thus imposed. People are 
inclined to give priority to the goals of these collectives over their own personal goals. Reference [37] argues that the collectivism-individualism dimension strongly influences what kind of information people prefer and are more prepared to process.

Uncertainty Avoidance Uncertainty avoidance can be conceptualized as the propensity of individuals to avoid actions where the outcome is unclear. Customs in cultures with high uncertainty avoidance include dichotomization (conceptualizing people and situations as either good or bad), modularation and compartmentalization of tasks, in an attempt to simplify them [13-40].

Masculinity/Femininity The concept of masculinity is associated with the competitiveness of individuals. Masculine individuals value ambition and the acquisition of wealth, while feminine individuals value nurturing and quality of life. Masculine individuals typically believe that failure is catastrophic, while feminine individuals see failure as common and find it easier to move on.

\section{National Culture and Knowledge Transfer}

National culture is a crucial factor in knowledge transfer. Cultures shape the value of both managers and employees. Cultural differences evoke subtle yet powerfully different managerial behaviors and leadership styles [41] Such behaviors and leadership styles provide the organizational context within which employees transfer their knowledge to one another.

As mentioned in above, national culture can be classified into four dimensions, which are Power distance, Individualism/Collectivism, Uncertainty avoidance, Masulinity/Femininity. These dimensions determine assumptions and behaviors of managers and employees in the process of knowledge transfer. According to several scholars [13-42], power distance and individualism/collectivism are the primary distinctions between North America (Canada and US) and China (Hong Kong and Mainland China). Reference [13] indicates that, the power distance scores of people in Hong Kong and China are much higher than that of people in North America, while the individualism scores of people in Hong Kong and China are much lower than that of people in North America. Thus, power distance and individualism/ collectivism are chosen as the representatives of national culture in this work and discuss in detail in the following.

Power Distance Power distance deals with leaders' decision power. It affects both the way in which people organize themselves and the way in which they write about organizing [12]. Power Distance is the degree to which people accept and expect unequal authority. Individuals who score high on power distance believe that supervisors should maintain decision making authority, receive credit for success, and that supervisors deserve respect and admiration from subordinates. Conversely, individuals who score low on power distance believe that the supervisor and the subordinate are colleagues, working toward the same goal, and are similar in terms of respectability. The superior position will improve decision power in high-power-distance culture while hardworking, good work and experiences are ways to increase decision power in low-power-distance culture [12-44].

Based on the above analysis, people from different Power Distance societies will act differently toward authority: the larger the power distance is, the more people would accept unequal authority. Hence, managers with different cultural backgrounds might play different roles in the process of inter-organizational knowledge transfer.

Individualism/Collectivism In individualistic societies, members have less respect and loyalty to the group they belong to than members of collectivist societies have. They prefer to stand on their own feet, favor independent work, emphasize competition and achieving specific statuses, and have a calculated involvement in group affairs. In contrast, members of collectivist societies respect and remain loyal to their group and emphasize cooperation and group work. They prefer low internal competition, relationships, harmony, order and discipline [42] and favor cooperation and teamwork [12-45].

Cultures shape the norms that define the context for social interaction [25]. Individualism and collectivism strongly influence ways of thinking. Specifically, they influence how members of a culture process, interpret, and make use of a body of information and knowledge [37]. Collectivists maintain respect, harmony, and loyalty to the groups they belong to and support order, discipline and centralized authority vested at the top. They are more likely to obey managers' orders and go along with their managers' wills. Furthermore, employees in collectivist societies rely on their supervisors while those in individualistic societies prefer to get help from their peers [46]. In addition, workers in individualist societies envision knowledge creation as an intervention of individual effort while workers in collectivist societies think of the integration and modification of existing knowledge as a group effort [46]. Thus, managers in collectivist societies will more thoroughly create the right context for knowledge sharing among different groups and better harmonize differences among the involved groups.

\section{Theoretical Conclusions, Limitations, and Future Research}

Knowledge and culture are indissolubly linked together in organizations. Considerable evidence supports the importance of culture in the success or failure of knowledge management.

Starting from the basic concept of the culture and knowledge and basing on the type of knowledge and the dimension of culture both influence knowledge-sharing, power distance and individualism/collectivism are cho- 
sen as the representatives of national culture in this work and discuss the effect of national culture on knowledge transfer.

This paper proposes two abstract conclusions: 1) people from different Power Distance societies will act differently toward authority: the larger the power distance is, the more people would accept unequal authority. Hence, managers with different cultural backgrounds might play different roles in the process of inter-organizational knowledge transfer. 2) Individualism and collectivism strongly influence ways of thinking. Collectivists maintain respect, harmony, and loyalty to the groups they belong to and support order, discipline and centralized authority vested at the top. Managers in collectivist societies will more thoroughly create the right context for knowledge sharing among different groups and better harmonize differences among the involved groups.

The research is limited by its scope because it focuses on the transfer processes. Further research might examine the culture factor influencing knowledge management in other knowledge management processes. There is also an unclear detailed relationship between knowledge management performance and knowledge management decision based on different culture dimensions. Further research might examine the relationship between organization performance and knowledge management decision based on different culture dimensions, as well as empirical research on the cultural conditions that lead to appropriate and inappropriate adaptation.

\section{REFERENCES}

[1] H. Takeuchi, "Towards a universal management of the concept of knowledge, managing industrial knowledge: Creation, transfer and utilization,” in I. Nonaka and D. J. Teece, Eds. London: Sage, 2001.

[2] B. L. Simonin, "Ambiguity and the process of knowledge transfer in strategic alliances," Strategic Management Journal, Vol. 20, No. 7, pp. 595-623, July 1999.

[3] A. K. Gupta and V. Govindarajan, "Knowledge flows within multinational corporations," Strategic Management Journal, Vol. 21, No. 4, pp. 473-496, April 2000.

[4] R. Jensen and G. Szulanski, "Stickiness and the adaptation of organizational practices in cross-border knowledge transfers,” Journal of International Business Studies, Vol. 35, No. 6, pp. 508-523, November 2004.

[5] N. Holden, "Knowledge management: Raising the specter of the cross-cultural dimension,” Knowledge and Process Management, Vol. 8, No. 3, pp. 155-163, July/September 2001.

[6] D. J. Pauleen and P. Murphy, "In praise of cultural bias," MIT Sloan Management Review, Vol. 46, No. 2, pp. 21-22, Winter 2005.

[7] S. C. Voel and C. Han, "Managing knowledge sharing in China: The case of Siemens ShareNet," Journal of Knowledge Management, Vol. 9, No. 3, pp. 51-63, 2005.
[8] N. Finestone and R. Snyman, "Corporate south africa: Making multicultural knowledge sharing work,” Journal of Knowledge Management, Vol. 9, No. 3, pp. 128-141, 2005.

[9] C. Grimm and K. Smith, "Strategy as action: 1ndustry rivalry and coordination," Cincinnati, OH: SouthWestern College Publishing, 1997.

[10] T. L. Friedman, "The world is flat: A brief history of the twenty-first century,” New York, NY: Farrar, Straus and Giroux, 2005.

[11] J. Li, L. Karakowsky and K. Lam, "East meets east and east meets west: The case of Sino-Japanese and SinoWest joint ventures in China,” Journal of Management Studies, Vol. 39, No. 6, pp. 841-863, September 2002.

[12] Hofdtese, "Management scientists are human,” Management Science, Vol. 40, No. 1, pp. 4-13, January, 1994.

[13] G. Hofstede, "Culture’s Consequences: International Differences in Work-related Values (2nd Edtion)," Thousand Oaks, CA: Sage, 2001.

[14] I. Nonaka, "A dynamic theory of organizational knowledge creation,” Organization Science, Vol. 5, No. 1, pp. 14-37, February 1994.

[15] J. C. Spender, "Making knowledge as the basis of a dynamic theory of the firm," Strategic Management Journal, Special Issues: Knowledge and the Firm, Vol. 17, pp. 45-62, Winter 1996.

[16] D. Vance, "Information knowledge and wisdom: The epistemic hierarchy and computer-based information systems," in Proceedings of the Third America's Conference on Information Systems, Indianapolis, August 1997.

[17] N. Kock and R. McQueen, "Knowledge and information communication in organizations: An analysis of core, support and improvement process," Knowledge and Process Management, Vol. 5, No. 1, pp. 29-40, March 1998.

[18] M. Zack, “Managing codified knowledge," Sloan Management Review, Vol. 40, No. 4, pp. 45-58, Summer 1999.

[19] F. I. Dretske, "Knowledge and the flow of information," Stanford, CA: CLSI Publications, 1999.

[20] I. Nonaka and V. Peltokorpi, “Objectivity and subjectivity in knowledge management-a review of 20 top articles," Knowledge and Process Management, Vol. 13, No. 2, pp. 73-82, 2006.

[21] R. McDermot, "Why information technology inspired but cannot deliver knowledge management," California Management Review, Vol. 41, No.4, pp. 103-117, Summer 1999.

[22] C. Frappaolo and S. Capshaw, "Knowledge management software: Capturing the essence of know-how and innovation,” Information Management Journal, Vol. 33 No. 3, pp. 44-48, July 1999.

[23] I. Nonaka and H. Takeuchi, "The knowledge creating company," New York, NY: Oxford University Press, 
1995.

[24] T. H. Davenport, D. W. Long, and M. C. Beers, "Successful knowledge management projects," Sloan Management Review, Vol. 39, No. 2, pp. 43-57, Winter 1998.

[25] D. W. De Long and L. Fahey, "Diagnosing cultural barriers to knowledge management," Academy of Management Executive, Vol. 14, No. 4, pp. 113-128, November 2000.

[26] R. Glazer, "Measuring the knower: Towards a theory of knowledge equity," California Management Review, Spring, Vol. 40, No. 3, pp. 175-194, 1998.

[27] R. Garud and P. R. Nayyar, "Transformative capacity: Continual structuring by intertemporal technology transfer," Strategic Management Journal, Vol. 15, No. 5, pp. 365-385, June 1994.

[28] G. Szulanski, "Exploring internal stickiness: Impediments to the transfer of best practice within the firm," Strategic Management Journal, Special Issue: Knowledge and the Firm, pp. 27-44, Vol. 17, Winter 1996.

[29] E. H. Schein, "Organizational culture and leadership," San Francisco, CA: Jossy-Bass Inc, 1985.

[30] G. Hofstede, B. Neuijen, D. D. Ohayv, and G. Sanders, "Measuring organizational cultures: A qualitative and quantitative study across twenty cases," Administrative Science Quarterly, Vol. 35, No. 2, pp. 286-316, June 1990.

[31] G. Johns, “Organizational behavior: Understanding and managing life at work," New York, NY: HarperCollins College Publishers, 1996.

[32] G. Hofstede, "Attitudes, values and organizational culture: Disentangling the concepts," Organization Studies, Vol. 19, No. 3, pp. 477-492, 1998.

[33] P. X. Meschi and A. Roger, "Cultural context and social effectiveness in international joint ventures," Management International Review, Vol. 34, No. 3, pp. 197-216, 1994.

[34] B. L. Kedia and R. S. Bhagat, "Cultural constraints on transfer of technology across nations: Implications for research in international and comparative management," Academy of Management Review, Vol. 13, No. 4, pp. 559-571, October 1988.

[35] R. T. Watson, T. H. Ho and K. S. Raman, "Culture: A fourth dimension of group support systems," Communications of the ACM, Vol. 37, No. 10, pp. 44-55, October 1994.
[36] M. Srite and E. Karahanna, "The role of espoused national culture values in technology acceptance,” MIS Quarterly, Vol. 30, No. 3, pp. 679-704, September 2006.

[37] R. S. Bhagat, B. L. Kedia, P. D. Harveston, and H. C. Triandis, "Cultural variations in the cross-border transfer of organizational knowledge: An integrative framework," Academy of Management Review, Vol. 27, No. 2, pp. 204-221, April 2002.

[38] H. C. Triandis, "Individualism and collectivism,” Boulder, CO: Westview, 1995.

[39] C. Triandis, "Vertical and horizontal individualism and collectivism: Theory and research implications for international comparative management,” in Advances in International Comparative Management, J. L. Cheng and R. B. Peterson, Eds., Stanford, CT and London: JAI Press Inc, Vol. 12, pp. 7-35, 1998.

[40] E. Hall, “Beyond Culture (2”d Edtion),” New York, NY: Anchor Books/Random House, 1989.

[41] J. Michael, "A conceptual framework for aligning managerial behaviors with cultural work values," International Journal of Commerce \& Management, Vol. 7, No. 3/4, pp. 81-102, 1997.

[42] I. Vertinsky, D. K. Tse, D. A. Wehrung, and K. Lee, "Organizational design and management norms: A comparatives study of managers' perceptions in the People's Republic of China, Hong Kong, and Canada," Journal of Management, Vol. 16, No. 4, pp. 853-867, December1990.

[43] C. W. Chow, T. M. Lindquist, and A. Wu, "National culture and the implementation of high-stretch performance standards: An exploratory study,” Behavioral Research in Accounting, Vol. 13, pp. 85-109, 2001.

[44] M. C. Marchese, "Matching management practices to national culture in India, Mexico, Poland, and the U.S," The Academy of Management Executive, Vol. 15, No. 2, pp. 130-132, May 2001.

[45] T. H. Cox, S. A. Lobel, and P. L. McLeod, "Effects of ethnic group cultural differences on cooperative and competitive behavior on a group task," Academy of Management Journal, Vol. 34, No. 4, pp. 827-847, December 1991.

[46] Y. Yoo and B. Torrey, "National culture and knowledge management in a global learning organization: The strategic management of intellectual capital and organizational knowledge,” New York, NY: Oxford University Press, Inc., 2002. 